\title{
Numerical Simulation and Design Validation of Ball Valve For class 150 bar using FEM
}

\author{
Mohan Kumar M, Kiran Kumar P \\ SJB Institute of technology, Bengaluru \\ Visvesvaraya Technological University \\ mohankumarm7411@gmail.com
}

\begin{abstract}
Valves are the gadget that regulate, directs and controls the flow of a fluids by various passage ways. Valve application are virtually used in every industrial process including boilers, mining, power generation, processing of oil, gas, petroleum, food manufacturing and many other fields. A ball valve is a flow block valve that controls the flow of a liquids by means of a rotary ball having a bore. In this Project, Geometric modelling of the ball valve is created by using CATIA software. Numerical simulation is carried out it with the help of finite element analysis method i.e. discretising the component by using ANSYS tool. Static Analysis of the ball valve is carried out by using ANSYS tool. These FEA result are validated through analytical calculations as per ASME standards. The main objective of this study is to design calculation of a ball valve as per ASME standard and compare the results with FEM.
\end{abstract}

Keywords: Ball valve, CATIA, FEM, ANSYS, ASME, stress analysis.

\section{Introduction}

A Ball valve is a valve that rotate bore ball to $90^{\circ}$ motion that used as a ball-shaped disk to shut or start the flow of fluid. During the opening and closing of the valve ball rotates $0^{0}$ to $90^{\circ}$ clockwise and anticlockwise controlling the direction of flow. Multiple port valve directs the way of fluid will go by regulating flow direction. Bolted trunnion ball valve is are suitable for large scale and high pressure application from class 150 bar to 2500 bar. Trunnion valve are suitable for various application such as water, steam, oil, liquefied gas, natural gas, coal gas, etc. Bolted valve are further classified as 2 piece forged trunnion, 3 piece forged trunnion, 2 piece cast trunnion, 3 piece cast trunnion. The main Body of valves are produced by Forging, body shape by plastic deformation under great pressure into high strength parts. The 2 piece forged ball valves are designed with excellent Mechanical properties, toughness, Reliability, yield strength, ductility, (used for critical applications). Major Materials used in bolted ball valve were stainless steel, carbon steel. 


\subsection{Literature Review}

Prof.S.R.Basavaraddi et.al [1] in this study describes that design and validation of ball valve. The components of valve are analysed using the finite element analysis. Engineering FEA analysis are validated with the theoretical calculations. The pressure acting inside the valve are analysed using the ANSYS workbench. Akshaychougul et.al [2] explained about quarter-turned valve straight through flow valves having a round closure element with round seats, and how sealing stress are generated. CAD modelling of Ball Valve Flange design is made by means of CATIA V5 application Static analysis of the Ball Valve, Shell body and Flange design is performed using ANSYS to find the stress for equivalent pressure. Swapnil B. Tandle, et.al [3]: static analysis of ball valve is carried out with Ansys. The analytical values are calculated from stress calculations analytically. 3D CAD model created in CAD workbench Creo 3.0. The static analysis carried Ansys workbench. The result from static analysis are validated with the experimental results. [4] discus about an alternative method of designing pressure vessels. [5] discus about valve and its torque. [6] the stress analysis of parts of Gate Valve. The component in the Gate Valve are valve Body, Gate Stem, and slab gate. Finite element analysis of Gate Valve. A model of each element of Gate Valve is done in CATIA and analysis in ANSYS the result obtained from FEM and analytical theory are compared. the present study involves designing of high pressure valve of nominal diameter $25 \mathrm{~mm}$ as per ASME Standards. "ASME B.16.5"

\subsection{Procedure}

The main aim of this project is to Design the component of the ball valve by analytical as per ASME standard 16.34 and validation of result with numerical solution. Design calculation of min valve thickness. Minimum flange thickness for Bolted body joint. 3D model of valve can be done by using CATIA-V5 model. STP formatted 3D model imported by ANSYS. Meshing and contact can be done through ANSYS. Numerical calculation of stress and deformation can be calculated by using ANSYS.

\section{Analytical calculation and design validation by using fem method for class 150 bar trunnion ball valve}

\section{1 valve body}

Considering valve diameter as per standard ASME: $80 \mathrm{~mm}$

Nominal pipe size (NPS): 3inch

Valve type: Bolted, Threaded

Operating fluid: water at $38^{\circ} \mathrm{C}$

Material: stainless steel, carbon fiber

Valve size and class: 150 bar (15 MPa) 
Wherever the allowable stress is not available in ASME section II, Part D, the allowable stress is calculated using the formula: $S=\min (0.25 \sigma u, 0.67 \sigma y)$

Table 1:minimal valve thickness

\begin{tabular}{|l|l|l|c|}
\hline $\begin{array}{l}\text { Pressure class } \mathrm{pc} \\
\text { In bar }\end{array}$ & $\begin{array}{l}\text { Diameter D } \\
\text { In } \mathrm{mm}\end{array}$ & $\begin{array}{l}\text { Thickness equation } \\
\text { Tm in } \mathrm{mm}\end{array}$ & TmInmm \\
\hline 150 & 80 & $T \mathrm{~m}=0.20^{*} \mathrm{~d}+4.5$ & 6.1 \\
\hline
\end{tabular}

\section{Check for Flange thickness:.}

Design as per ASME/ANSI standard for design of Pipe Flanges \& Flanged Fittings-ASME B16.5. Selection of Flange from Pressure-Temperature Rating for Flange selection and hence the selected flange for Class 150 Flange [9].

Table 2:flange thickness

\begin{tabular}{|c|c|}
\hline $\begin{array}{l}a=\text { Radius of PCD, } 76.25 \mathrm{~mm} \\
\mu-0.278 \text {, } \\
P=\text { Pressure } 150 \text { bar }(15 \mathrm{MPa}) \\
\mathrm{f}=\text { Allowable stress, } 138 \mathrm{MPa} \\
\mathrm{t}=\text { Thickness of flange, } \mathrm{mm} \text { Pitch circle diameter }=152.5 \mathrm{~mm} \\
\text { thickness } \mathrm{t}=27.87 \mathrm{~mm}\end{array}$ & $\begin{array}{l}\text { 1)t }=a * \sqrt[2]{\frac{3(3+\mu) p}{8 f}} \\
\mathrm{t}=76.25 * \sqrt[2]{\frac{3(3+0.278) 15}{8 * 138}} \\
\mathbf{t}=\mathbf{2 7 . 8 7} \mathbf{~ m m}\end{array}$ \\
\hline $\begin{array}{l}\mathrm{P}=\text { Pressure acting, } 150 \mathrm{bar}(15 \mathrm{MPa}) \\
\mathrm{f}=\text { Allowable stress, } 138 \mathrm{MPa} \\
\text { nominal diameter }=80 \mathrm{~mm}\end{array}$ & $\begin{array}{l}\text { 2) } t=\frac{P * D}{2 * F}+3.3 \\
\quad t=\frac{15 * 80}{2 * 138}+3.3 \\
\mathbf{t}=\mathbf{7 . 6 4} \mathbf{~ m m} \\
\text { Selected Flange thickness is } \\
\mathbf{t}=\mathbf{2 7 . 8 7} \mathbf{m m}>\mathbf{7 . 6 4 m m} \\
\text { Hence Design is safe. }\end{array}$ \\
\hline
\end{tabular}




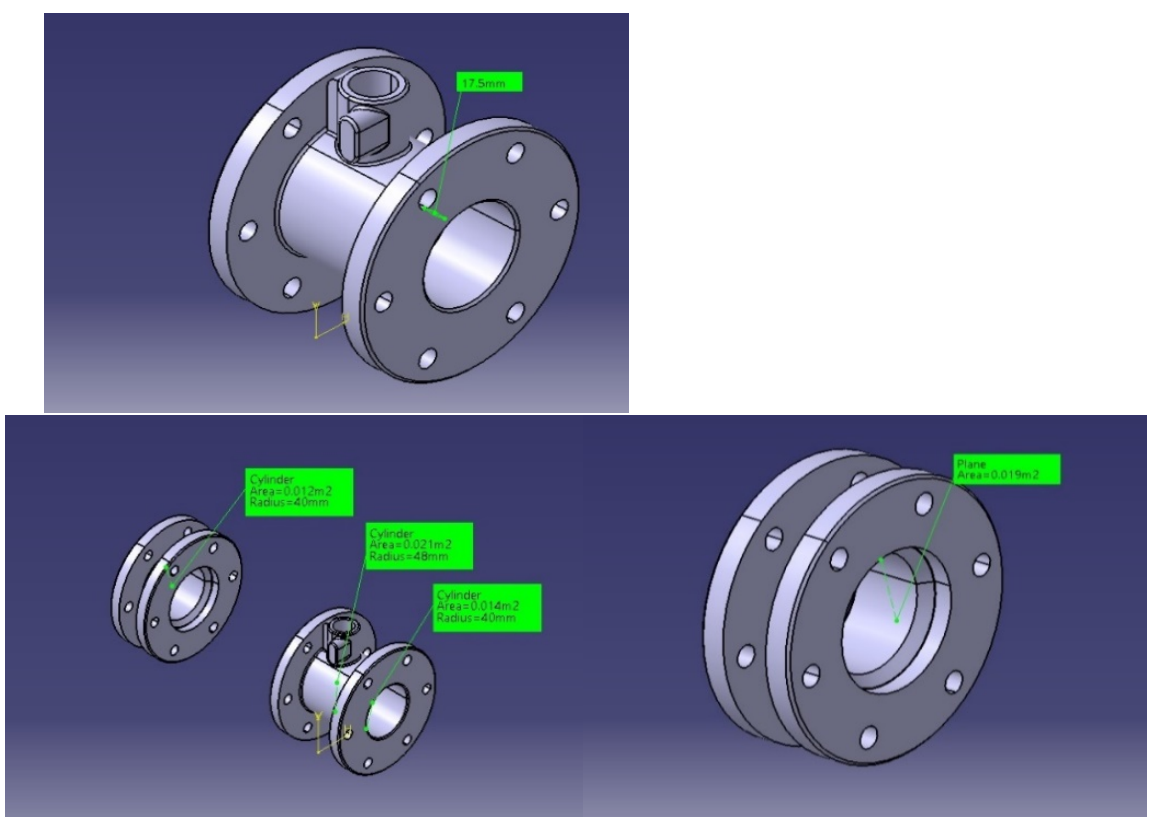

Fig -1: Flange thickness for class 150 bar, Fig -2: Ag - Area bounded by sealeffective periphery for class 150 bar, Fig -3: Ab- Total effective bolt tensile stress area for class 150 bar

\section{Bolted body joint is designed based on B16.34}

$\mathrm{Pc} *(\mathrm{Ag} / \mathrm{Ab}) \leq \mathrm{K} 2 * \mathrm{~S}_{\mathrm{a}} \leq 7000$

$\mathrm{Ab}=$ total effective bolt tensile stress area of valve body.

$\mathrm{Ag}=$ area bounded outside periphery of a gasket.

$\mathrm{K} 1=65.26 / \mathrm{MPa}$ when $\mathrm{S}_{\mathrm{a}}$ is expressed in MPa units.

$\mathrm{Pc}=$ pressure rating class designation

$\mathrm{S}_{\mathrm{a}}=$ allowable stress at $38^{\circ} \mathrm{C} \mathrm{MPa}$

Table 3.design bolted joint

\begin{tabular}{|l|c|}
\hline $\mathrm{Pc}=15.00 \mathrm{MPa}$ & $\mathrm{Pc} *(\mathrm{Ag} / \mathrm{Ab}) \leq \mathrm{K} 2 * \mathrm{~S}_{\mathrm{a}} \leq 7000.00$ \\
$\mathrm{Ag}=47000.00$ & $15.00 *(47000.00 / 19000.00) \leq 50.76 * 120$ \\
$\mathrm{~mm}^{\wedge} 2$ & $\leq 7000.00$ \\
$\mathrm{Ab}=19000.00 \mathrm{~mm}^{\wedge} 2$ & $37.10 \leq 6091.12 \leq 7000.00 \mathrm{MPa}$ \\
$\mathrm{K} 2=50.76$ & Hence design is SAFE \\
$\mathrm{S}_{\mathrm{a}}=120.00 \mathrm{MPa}$ & \\
&
\end{tabular}




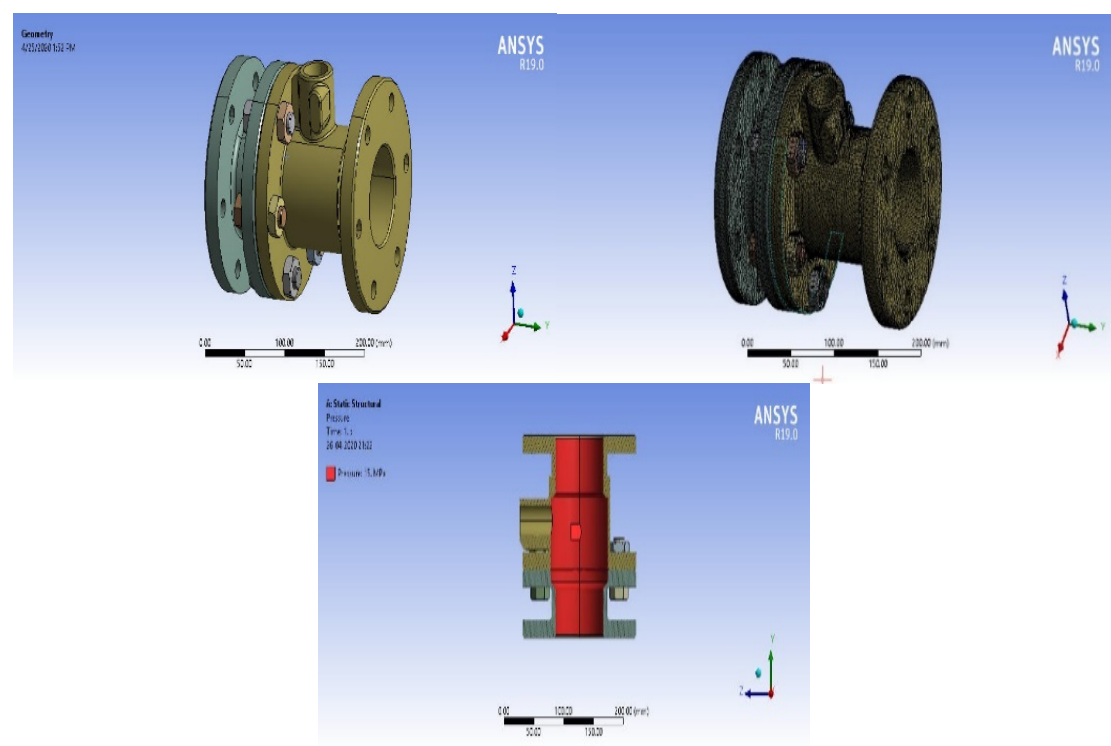

Fig -4: Imported model from CATIA to Ansys for class 150 bar, Fig -5: Meshing model for class 150 bar Fig -6: Applied pressure - $15 \mathrm{MPa}$ (150 bar)

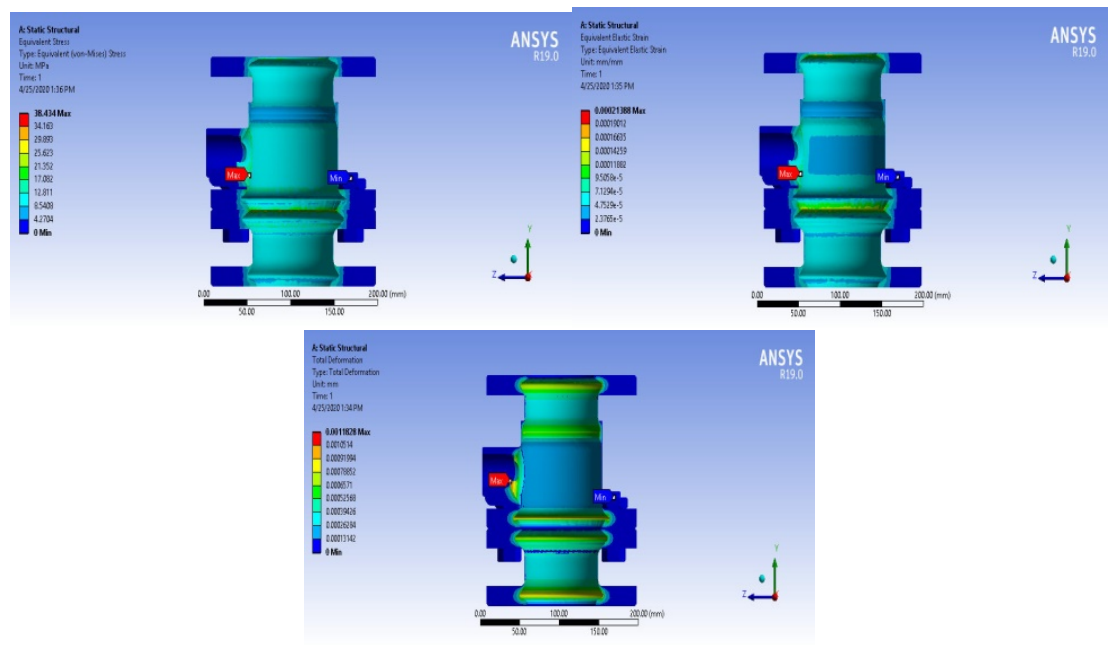

Fig -7: Equivalent von-mises stress for 150 bar pressure, Fig -8: Equivalent elastic strain for 150 bar pressure Fig -9: Total deformation for 150 bar pressure 


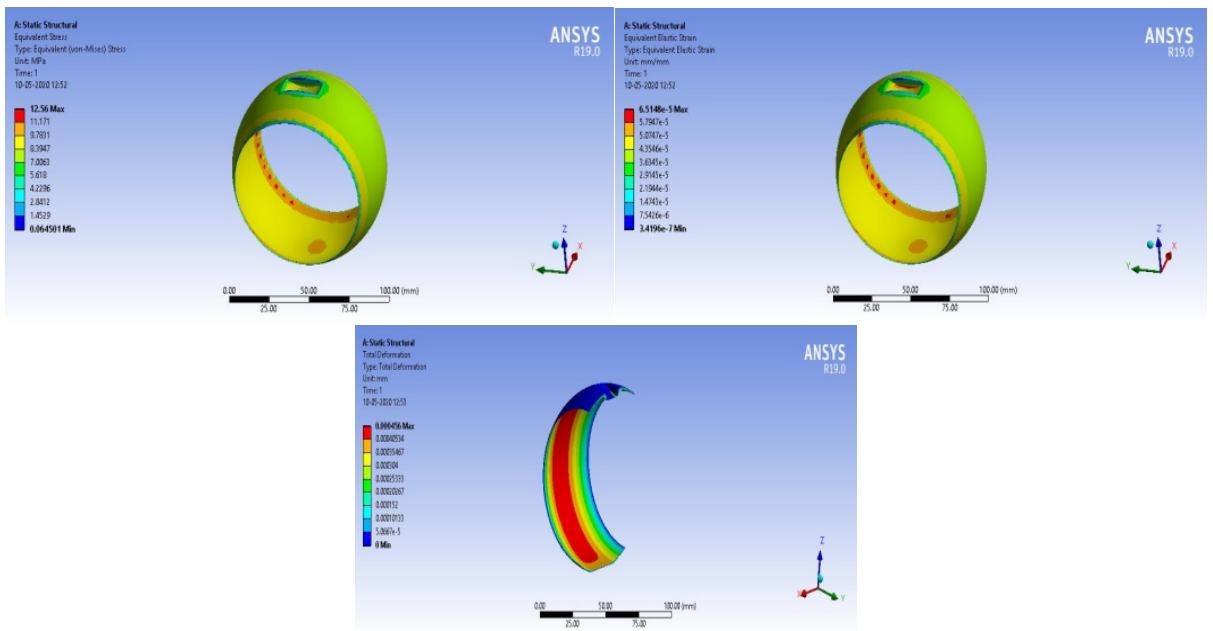

Fig -13: Valve ball Equivalence von-mises stress for 150bar (15 MPa) Fig -14: Valve ball equivalent elastic strain for 150bar (15 MPa) Fig -15: Valve ball- total deformation for 150bar $(15 \mathrm{MPa})$

\section{Conclusion}

\subsection{Valve body}

Equivalent von-mises stress In MPa

\begin{tabular}{|c|c|c|}
\hline $\begin{array}{c}\text { Analytica } \\
1\end{array}$ & \multicolumn{2}{|c|}{$\begin{array}{c}\text { Numerical } \\
\text { value }\end{array}$} \\
\hline 37.10 & Max & Mi \\
& & $\mathrm{n}$ \\
\cline { 2 - 3 } & 38.43 & 0 \\
4 & \\
\hline
\end{tabular}

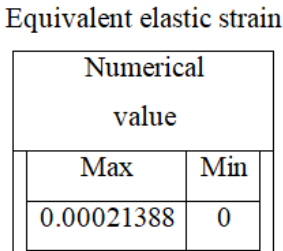

Total deformation in $\mathrm{mm}$

\begin{tabular}{|c|c|}
\hline \multicolumn{2}{|c|}{$\begin{array}{c}\text { Numerical } \\
\text { value }\end{array}$} \\
\hline Max & Min \\
\hline 0.0011828 & 0 \\
\hline
\end{tabular}




\subsection{Valve Ball}

\begin{tabular}{|c|c|}
\hline \multicolumn{2}{|c|}{ Equivalent von-mises stress In } \\
$\mathrm{MPa}$
\end{tabular}

\begin{tabular}{|c|c|c|}
\hline & Max & Min \\
\cline { 2 - 3 } & $6.5148 * 10-5$ & $3.4196 * 10-7$ \\
\hline
\end{tabular}

\begin{tabular}{|c|}
\hline Equivalent elastic strain \\
\hline Numerical value \\
\hline
\end{tabular}

\begin{tabular}{|c|c|}
\hline \multicolumn{2}{|c|}{$\begin{array}{l}\text { total deformation in } \\
\mathrm{mm}\end{array}$} \\
\hline $\begin{array}{r}\text { Numeri } \\
\text { value }\end{array}$ & \\
\hline Max & Min \\
\hline 0.000456 & 0 \\
\hline
\end{tabular}

\section{References}

1. Prof. S R Basavaraddi ET.AL, "conceptual design and analysis of high pressure ball valve," IRJET, no. ISSSN : 2395-0072.

2. Akshay cholugal ET.AL, "study of ball valve and design o thickness of shell and falnge," IRJET, no. e- ISSN :2395-0056.

3. swapnil B.tandle et.al, "Design \& analysis of ball valve," IJSETR, no. ISSN :2278-7798.

4. Hitesh Raiyani ET.AL, "alalysis and optimization of ball valve," IJIRSET, no. ISSN: 23198753.

5. S. T. Ahmed, H. K. Priyanka, S. Attar and A. Patted, "Cataract density ratio analysis under color image processing approach," 2017 International Conference on Intelligent Computing and Control Systems (ICICCS), Madurai, 2017, pp. 178-180, doi: 10.1109/ICCONS.2017.8250705.

6. Sreedhar Kumar S, Syed Thouheed Ahmed, NishaBhai, Vinutha B A, "Type of Supervised Text Classification System for Unstructured Text Comments using Probability Theory Technique", International Journal of Recent Technology and Engineering (IJRTE), Vol.8, No.10, DOI:10.35940/ijrte.B1158.0982S1019, 2019. 